BMJ Open

Diabetes

Research

\& Care

\section{Person-centered diabetes care and patient activation in people with type 2 diabetes}

To cite: Rutten GEHM, Van Vugt $\mathrm{H}$, de Koning $\mathrm{E}$. Person-centered diabetes care and patient activation in people with type 2 diabetes. BMJ Open Diab Res Care 2020;8:e001926. doi:10.1136/ bmjdrc-2020-001926

Received 28 September 2020 Revised 19 November 2020 Accepted 21 November 2020

Check for updates

\section{(c) Author(s) (or their} employer(s)) 2020. Re-use permitted under CC BY-NC. No commercial re-use. See rights and permissions. Published by BMJ.

${ }^{1}$ Department of General Practice, Julius Center for Health Sciences and Primary Care, University Medical Center Utrecht, Utrecht, Netherlands ${ }^{2}$ Department of Internal Medicine, Division of Endocrinology, Leiden University Medical Center, Leiden, Netherlands

Correspondence to Professor Guy E H M Rutten; g.e.h.m.rutten@umcutrecht.nl

\section{ABSTRACT}

Introduction The American Diabetes Association and the European Association for the Study of Diabetes advocate a person-centered approach to enhance patient engagement in self-care activities. To that purpose, people with diabetes need adequate diabetes knowledge, motivation, skills and confidence. These prerequisites are captured by the concept 'patient activation'. The Dutch Diabetes Federation implemented a person-centered consultation model for the annual diabetes review. To assess its relationship with patient activation, we measured the change in patient activation, and in person and disease-related factors in people with type 2 diabetes after their second personcentered annual review.

Research design and methods Observational study in 47 primary care practices and six outpatient hospital clinics. Follow-up: 1 year. From 2.617 people with diabetes and capable of completing questionnaires (no additional exclusion criteria) 1.487 (56.8\%) participated, 1366 with type 2 diabetes. Main outcome: patient activation (13-item Patient Activation Measure, score 0-100). Before the first and after the second review, participants completed questionnaires. Medical data were retrieved from electronic records. We performed a repeated measure analysis using a linear mixed model in 1299 participants, who completed the first set of questionnaires.

Results In 1299 participants (41.6\% female, mean age 66 years, median diabetes duration 10 years, median glycated hemoglobin $(\mathrm{HbA} 1 \mathrm{c}) 6.8 \% / 51 \mathrm{mmol} / \mathrm{mol})$, the mean baseline activation level was 58.9 (SD 11.7). Independent of actual diabetes care, activation levels increased 1.53 units $(95 \% \mathrm{Cl} 0.67$ to $2.39, \mathrm{p}=0.001)$. Several diabetes perceptions improved significantly; diabetes distress level decreased significantly. Body mass index $(-0.22,95 \%$ $\mathrm{Cl}-0.33$ to $-0.10, \mathrm{p}<0.001)$ and low-density lipoprotein cholesterol $(-2.71 \mathrm{mg} / \mathrm{dL}, 95 \% \mathrm{Cl}-4.64$ to -0.77 , $\mathrm{p}=0.004)$ decreased, $\mathrm{HbA} 1 \mathrm{c}$ increased $0.08 \%(95 \% \mathrm{Cl}$ 0.03 to 0.12$)(p=0.001)$.

Conclusions Person-centered diabetes care was associated with a slightly higher patient activation level, improved diabetes perception and small improvements in clinical outcomes. Person-centered care may enhance patient engagement, but one should not expect substantial improvement in patient outcomes in the short term.

\section{INTRODUCTION}

The American Diabetes Association (ADA) and the European Association for the Study of Diabetes (EASD) advocate a person-centered

\section{Significance of this study}

What is already known about this subject?

- International diabetes organizations advocate person-centered diabetes care with shared decision-making. So-called patient activation is a prerequisite.

- A PubMed search in 2015 revealed that evidence supporting the effectiveness of person-centered care is scarce.

What are the new findings?

- After the second person-centered annual review, people with type 2 diabetes reported a higher activation level, better illness perception and a lower diabetes distress level compared with their baseline state; body mass index and low-density lipoprotein cholesterol decreased, HbA1c increased. All changes were small.

How might these results change the focus of research or clinical practice?

- Diabetes care providers may be stimulated to follow the American Diabetes Association/European Association for the Study of Diabetes decision cycle for patient-centered diabetes care.

approach to enhance patient engagement in self-care activities. ${ }^{1}$ Glycemic targets must be individualized in the context of shared decision-making (SDM) to address the needs and preferences of each patient and the individual characteristics that influence risks and benefits of therapy for each patient. ${ }^{2}$ Specifically, diabetes care should include a regular review of a person's problems in relation to individual circumstances and focus on (1) quality of life and function in addition to disease control, (2) tailoring of treatment recommendations to each individual's priorities and situation, (3) achieving a balance between the risks and benefits of treatment, (4) promotion of self-management and SDM, and (5) agreement regarding an individualized care plan. ${ }^{3}$ In this way, all factors known to determine diabetes self-management are addressed. ${ }^{4}$ 


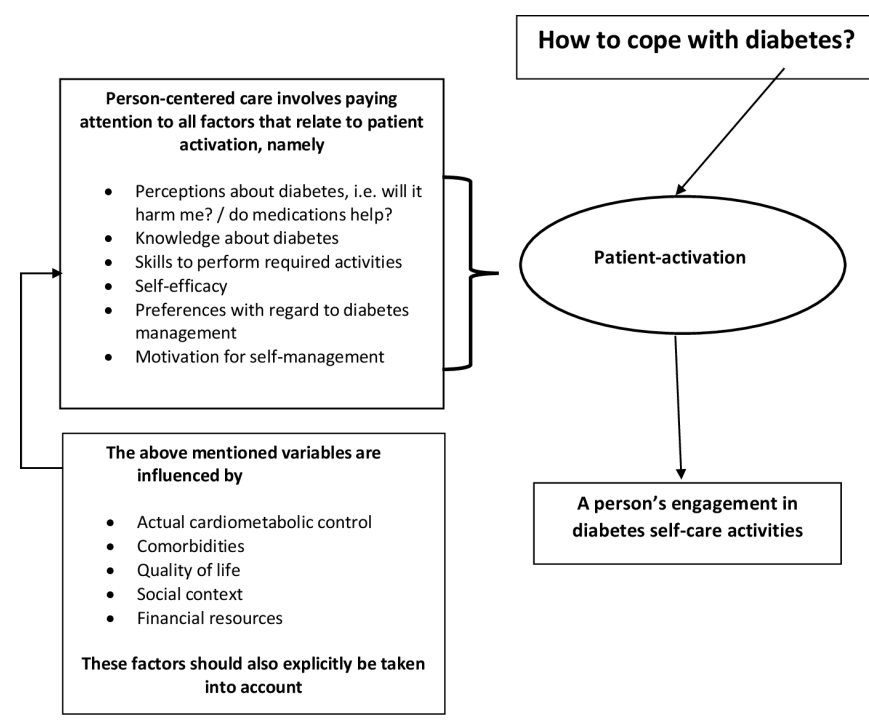

Figure 1 The supposed relationship between personcentered care and a person's engagement in diabetes selfcare activities.

To get engaged in self-management, people with diabetes need adequate diabetes knowledge, motivation, skills and confidence ${ }^{5}$ (figure 1). These prerequisites are captured by the concept 'patient activation' and measured with the Patient Activation Measure (PAM) ${ }^{6}$ that divides the activation spectrum into four levels. In the first stage, the individual believes an active role is important for disease management. In the second stage, he or she has the knowledge and the confidence to take action; in the third stage, the patient actually takes action. Finally, the patient is able to maintain adequate behavior, even when under stress. ${ }^{7}$ The main difference between patient activation and patient education refers to the patient's active role in decision-making. ${ }^{6}$ Evaluations of interventions to increase patient activation have been carried out in hospitals, disease management programs and primary care $(\mathrm{PC})$. Interventions ranged in duration from just one visit to periods of 6 months. All of these studies have documented improvements in activation scores as a result of the intervention being tested. On average, improvements ranged from 2.5 to 6.5 points on the 100-point activation scale. Concurrent with the increases in activation, several of the studies have shown improvements in health outcomes, for example, healthrelated quality of life, therapy adherence, low-density lipoprotein (LDL) levels and blood pressure. ${ }^{8}$ Interventions targeted at patient activation in adults with type 2 diabetes showed a positive effect on glycemic control and self-management behavior. ${ }^{9}$

Although person-centered approaches, professional skills training and personal goal setting have been suggested as effective ingredients to facilitate diabetes self-management education and support, ${ }^{10}$ it is not clear whether person-centered diabetes care improves peoples' engagement.
The Dutch Diabetes Federation implemented a fourstep person-centered consultation model for the annual diabetes review. First, the person with type 2 diabetes and the care provider discuss person and disease-related factors relevant to the person's actual situation, for example, the quality of life, illness perceptions, preferences, diabetes knowledge and skills and the actual cardiometabolic control. In steps 2-4, shared decisions are made on type and extent of professional diabetes care for the following year. To stimulate their engagement, people are recommended to prepare some questions before the review. We could demonstrate that $72 \%$ of such consultations could be performed within $25 \mathrm{~min}$, both in PC and in secondary care (SC). Between $80 \%$ and $90 \%$ of both the people with type 2 diabetes and their care providers stated that shared decisions on treatment had been made. ${ }^{11}$

To assess the relationship between person-centered diabetes care and patient activation, we measured the change in patient activation, and in person and diseaserelated factors in people with type 2 diabetes after their second person-centered annual diabetes review.

\section{RESEARCH DESIGN AND METHODS}

\section{Study design}

This before-after implementation study assessed the change in patient activation in daily diabetes care after two annual reviews. Physicians and nurses were trained in the application of the consultation model two times during 2 hours. We also measured the change in people's illness perceptions and self-reported self-care activities. Besides, we measured other person and disease-related factors, most of which belonging to a core list of standard outcomes for diabetes to be routinely applied. ${ }^{12}$ The study was performed between 1 November 2015 and 1 March 2018.

\section{Study population}

As many as possible general practices and outpatient clinics were included during the fixed inclusion period (November 2015 to February 2017). In total, 47 general practices (57 PC physicians and 23 practice nurses) and 6 outpatient clinics (17 internal medicine specialists and 8 specialist diabetes nurses) participated. Of the 47 general practices, $43 \%$ were located in a city with $>50.000$ inhabitants; and $57 \%$ in the urbanized countryside or rural areas. Compared with national data, group practices with three or more PC physicians ( $51 \%$ vs $39 \%$ ) were slightly over-represented. ${ }^{11}$ Two of the six participating outpatient clinics were from university hospitals. The mean age (SD) of the diabetes care providers was 46.8 years $(9.5$ years). About half of the physicians and more than $90 \%$ of the nurses were female. Participating PC physicians and the nurses were representative with regard to age and sex. Participating internal medicine specialists were on average 3 years older compared with the total group 
of Dutch internal medicine specialists and more often female. ${ }^{11}$

A total of 2.617 adults with type 1 and type 2 diabetes and capable of completing questionnaires were invited to participate. There were no additional exclusion criteria. Of them, $1.487(56.8 \%)$ participated, 1366 with type 2 diabetes. ${ }^{11}$ They received a letter describing the study. If willing to participate, they were asked to prepare for the annual consultation by answering four questions: (1) Do you have health problems? (2) Would you like to solve your health problems? (3) How would you like to do that? (4) What type of support do you need? ${ }^{11}$

\section{Participant questionnaires}

In the week before the first and within a week after the second annual review, participants were requested to complete a set of questionnaires. Sex, ethnicity, marital status, level of education, employment status, diabetes duration, comorbidities, and a statement on social support ('People around me support me when I have health-related problems') were only covered at the first review. Before the first and after the second review, participants answered a question concerning alcohol use ('yes/ no') and completed the following questionnaires:

1. The PAM-13, a 13-item measure that assesses person's self-reported knowledge, skills, and confidence regarding self-management. The PAM-13 is both reliable and valid. ${ }^{13}$ Item scores range from 0 'not applicable'; 1 'strongly disagree'; 2 'disagree'; 3 'agree' to 4 'strongly agree'. The mean PAM-13 score is transformed into a score ranging from 0 to 100 , with a higher score reflecting higher activation. We used the translated Dutch version. ${ }^{14}$ An improvement in 4 points on the PAM scale is considered a minimal clinically important difference (MCID). ${ }^{15}$

2. The EuroQol-5 Dimension (EQ-5D), a generic health status questionnaire that covers mobility, self-care, daily activities, pain/discomfort, and anxiety/depression. All five items can be rated from no problems to severe problems. The total score ranges from -0.33 to 1.00 , with a lower score reflecting a worse health status. ${ }^{16}$

3. The Audit of Diabetes-Dependent Quality of Life (ADDQoL) that measures the impact of diabetes and diabetes treatment on quality of life. It consists of 19 questions from which an average weighted impact is calculated that ranges from -9 to 3 ; a lower score indicating a more negative influence of diabetes on quality of life. ${ }^{17}$

4. The Brief Illness Perception Questionnaire (BIPQ) that measures illness perceptions and consists of eight items: consequences, timeline, personal control, treatment control, identity, illness concern, coherence and emotional representation. The BIPQ has just one single item to assess each dimension. All dimensions are rated on a $0-10$ scale. Higher scores indicate stronger perceptions along that dimension. ${ }^{18}$

5. The 5-item Problem Areas In Diabetes scale (PAID-5), a questionnaire on diabetes-related distress. The five items are rated from 0 (not a problem) to 4 (serious problem). The total score ranges from 0 to 20, higher scores indicating higher distress. A total score of $\geq 8$ may indicate severe diabetes-related distress. ${ }^{19}$

6. The Summary of Diabetes Self-Care Activities measure, with a score ranging from 0 to 7 that reflects the number of days in the previous week in which a selfcare activity has been carried out. Four self-care activities were included: general diet, physical exercise, blood glucose testing, and foot care, together with one question on smoking status. ${ }^{20} \mathrm{~A}$ higher score indicates more self-care activities.

\section{Other variables}

Data on age, glycated hemoglobin (HbA1c), LDL cholesterol, blood pressure and body mass index (BMI) at the first and second annual reviews were retrieved from people's electronic health records. The healthcare provider supplied data on the use of blood glucose, lipid and blood pressure-lowering medications.

\section{Statistical analysis}

Because the intervention, that is, the consultation model, did not specifically aim at improving patient activation, we would like to assess whether the model could result in any positive change in patient activation, clinically relevant or not. Besides, we strived for the inclusion of as many patients as possible in this implementation study. A power analysis showed that a sample size of 900 participants would be sufficient to demonstrate a difference of 0.01 on the PAM scale, with an SD of 1.0 (two sided), an alpha of 0.05 and a power of 0.90 . Continuous normally distributed data are presented as means with their SD, and continuous non-normally distributed data as medians with their $25 \%-75 \%$ IQR. Categorical data are presented as counts and percentages. To compare responders who completed the second questionnaire with those who did not, we used Student's t-test, Mann-Whitney U test or $\chi^{2}$ test when appropriate.

Because of the hierarchical structure of the design, with several people treated by the same diabetes care provider and with two assessments per person, outcomes of different people may be correlated. Therefore, we used a repeated measure analysis in a linear mixed model, which allows inclusion of all available data and handles missing data. The model had a random intercept and the fixed factors were time (difference between the first and second assessments), treatment setting and their interaction. We adjusted for treatment setting because participants differed between PC and SC with regard to illness duration, number of comorbid conditions, $\mathrm{HbAlc}$ level, systolic blood pressure, BMI, frequency of blood glucose monitoring, foot care, EQ-5D, ADDQoL, PAID and BIPQ. ${ }^{20}$ Additionally, we adjusted for the differences between participants who did or did not complete the second set of questionnaires.

Participants who answered less than 10 questions in the PAM-13 or answered all 13 questions with 'strongly 
67 patients did not complete the questionnaire

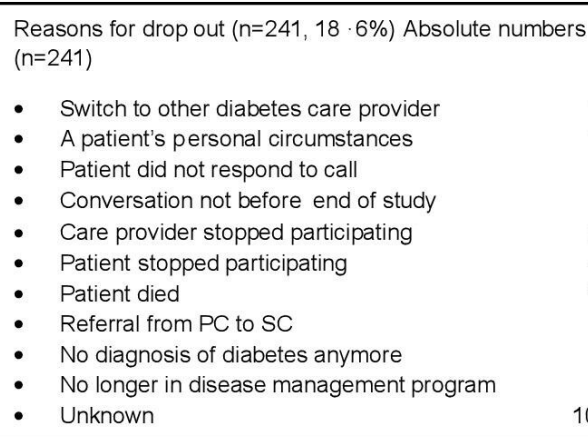

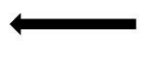

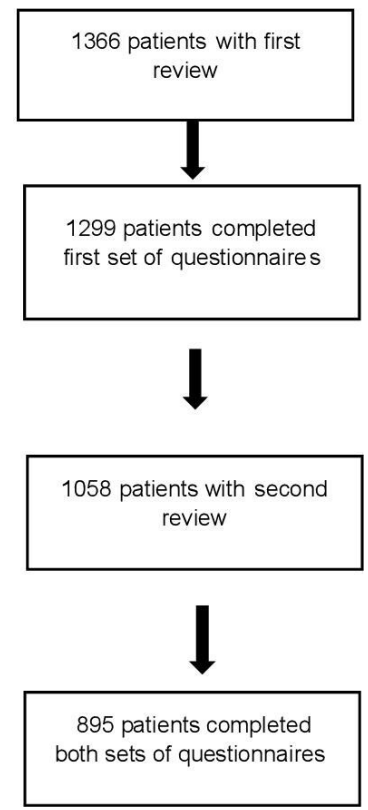

Figure 2 Patient flow chart. PC, primary care; SC, secondary care.

disagree' or 'strongly agree' were excluded from the analyses. ${ }^{21}$ If a question was indicated as 'not applicable', this response was treated as missing data. ${ }^{22} 23$ Analyses were performed using SPSS V.23.0 (SPSS). P $<0.05$ was considered significant.

\section{RESULTS}

From the 1.366 participants with type 2 diabetes, 1.299 $(95.1 \%)$ completed the first set of questionnaires, 1058 took part in the second review (mean follow-up 54.2 weeks; SD 9.2) and 895 (68.9\%) also completed questionnaires following this review (figure 2). Participants who completed the second set of questionnaires $(n=895)$ were slightly older (mean 66.5 vs 65.1 years, $\mathrm{p}=0.016$ ) and had a slightly lower HbA1c (median $6.8 \%$ vs $7.0 \%$, p=0.002) than those who did not $(n=404)$.

Table 1 shows the baseline characteristics of all analyzed participants $(n=1299)$. Their mean age was 66.0 (9.8) years, $41.6 \%$ were female, 1 out of 5 was highly educated and almost 1 in 3 had a paid job. People had a median diabetes duration of 10 years (IQR 5-16 years) and one comorbid condition (IQR 1-3). Overall, they were well controlled, with $19.2 \%$ not using blood glucose-lowering medication. Almost $80 \%$ of the people used lipid-lowering medication and $77.5 \%$ antihypertensive medication. The mean activation level of people was 58.9 (11.7). Mean scores on the perceptions conscious of diabetes duration (8.5), personal control (6.8), treatment control (7.5), and understanding of diabetes (coherence) (7.0) were relatively high. The mean scores regarding experience of symptoms of the disease (identity) and impact of the disease (emotional representation) were low.

\section{Patient activation, diabetes perception and diabetes-related} distress

Table 2 shows the differences between the first and second assessments. Independent of whether people were treated in PC or SC and adjusted for age and $\mathrm{HbAlc}$, their activation measure (PAM) increased slightly but significantly. Peoples' perception of the consequences of diabetes, the feeling of personal control of their diabetes and a coherent understanding of diabetes all improved significantly, and distress levels significantly decreased.

\section{Biomedical variables}

Although self-care activities did not change, LDL cholesterol and BMI decreased significantly. HbA1c level increased $0.08 \%$ (95\% CI 0.03 to 0.12 ) ( $\mathrm{p}=0.001$ ). People who were treated in $\mathrm{PC}$ were more likely to have slightly worse glycemic control at the second review $(\mathrm{p}=0.042)$.

\section{CONCLUSIONS}

In this 'real world' evaluation of a person-centered approach in diabetes care, people with type 2 diabetes were found to have a significantly higher activation level and lower distress levels after two annual reviews. However, absolute changes were small.

The mean activation measurement of participants just before the implementation of the consultation model (58.9) was lower than the mean (61.3) of a larger Dutch sample of people with a chronic disease, ${ }^{24}$ but comparable to another population of Dutch people with type 2 diabetes (59.1) ${ }^{25}$ From patients in four European countries, the 1829 Dutch patients with a chronic illness had the lowest mean PAM score of 61.2 (SE 0.34) ${ }^{26}$ In a large and diverse sample of 4865 American people with chronic conditions (29\% diabetes), the mean PAM score at baseline in patients with diabetes was 65.4 (no SD available) 
Table 1 Characteristics of the study population at baseline

\begin{tabular}{|c|c|c|}
\hline Characteristic & $\mathbf{n}$ & \\
\hline Age, mean (SD), years & 1298 & $66.0(9.8)$ \\
\hline Female sex, \% & 1289 & 41.6 \\
\hline Ethnicity, Caucasian, \% & 1288 & 92.9 \\
\hline $\begin{array}{l}\text { Marital status (married or } \\
\text { cohabitating), } \%\end{array}$ & 1291 & 76.5 \\
\hline $\begin{array}{l}\text { Educational level (low/ } \\
\text { intermediate/high), \% }\end{array}$ & 1281 & $34.4 / 44.9 / 20.7$ \\
\hline $\begin{array}{l}\text { Employment status (having } \\
\text { a job), \% }\end{array}$ & 1254 & 28.8 \\
\hline Smoking, \% & 1272 & 12.4 \\
\hline Alcohol use (yes), \% & 1266 & 47.3 \\
\hline PAM score, mean (SD) & 1188 & $58.9(11.7)$ \\
\hline EQ-5D score, median (IQR) & 1208 & $0.84(0.78-1.00)$ \\
\hline $\begin{array}{l}\text { ADDQoL score, median } \\
(\mathrm{IQR})\end{array}$ & 1246 & $\begin{array}{l}-0.36(-1.19 \text { to } \\
-0.06)\end{array}$ \\
\hline \multicolumn{3}{|l|}{ BIPQ, mean (SD) } \\
\hline Consequence & 1259 & $4.1(2.7)$ \\
\hline Timeline & 1229 & $8.5(2.4)$ \\
\hline Personal control & 1258 & $6.8(2.2)$ \\
\hline Treatment control & 1245 & $7.5(2.2)$ \\
\hline Identity & 1259 & $3.5(2.7)$ \\
\hline Illness concern & 1261 & $4.7(3.0)$ \\
\hline Coherence & 1248 & $7.0(2.2)$ \\
\hline Emotional representation & 1257 & $3.1(2.9)$ \\
\hline PAID score, median (IQR) & 1261 & $3(1-7)$ \\
\hline \multicolumn{3}{|l|}{ SDSCA, mean (SD) } \\
\hline General diet & 1199 & $4.7(1.9)$ \\
\hline Physical exercise & 1217 & $4.0(2.0)$ \\
\hline Blood glucose testing & 1154 & $1.4(2.3)$ \\
\hline Foot care & 1202 & $1.6(2.1)$ \\
\hline $\begin{array}{l}\text { Treatment setting (PC/SC), } \\
\%\end{array}$ & 1299 & $87.9 / 12.1$ \\
\hline $\begin{array}{l}\text { Diabetes duration, median } \\
\text { (IQR), years }\end{array}$ & 1208 & $10(5-16)$ \\
\hline $\begin{array}{l}\text { Number of comorbidities, } \\
\text { median (IQR) }\end{array}$ & 1267 & $1(1-3)$ \\
\hline HbA1c, median (IQR), \% & 1231 & $6.8(6.4-7.5)$ \\
\hline $\begin{array}{l}\text { LDL cholesterol, mean (SD), } \\
\mathrm{mg} / \mathrm{dL}\end{array}$ & 1203 & $92.8(30.9)$ \\
\hline $\begin{array}{l}\text { Systolic blood pressure, } \\
\text { mean (SD), mm Hg }\end{array}$ & 1228 & 136.7 (15.6) \\
\hline BMI, median (IQR), kg/m² & 1224 & $29.3(26.4-33.1)$ \\
\hline $\begin{array}{l}\text { Blood glucose-lowering } \\
\text { medication, } \%\end{array}$ & 1221 & \\
\hline No medication & & 19.2 \\
\hline Oral medication only & & 56.1 \\
\hline
\end{tabular}

Continued

\begin{tabular}{lll} 
Table 1 Continued & \\
\hline Characteristic & $\mathbf{n}$ & \\
\hline $\begin{array}{l}\text { Insulin monotherapy } \\
\text { or insulin and oral } \\
\text { medication }\end{array}$ & 24.7 \\
$\begin{array}{l}\text { Lipid-lowering medication, } \\
\%\end{array}$ & 1219 & 78.8 \\
$\begin{array}{l}\text { Blood pressure-lowering } \\
\text { medication, \% }\end{array}$ & 1220 & 77.5 \\
\hline
\end{tabular}

ADDQoL, Audit of Diabetes-Dependent Quality of Life; BIPQ, Brief Illness Perception Questionnaire; BMI, body mass index; EQ-5D, EuroQol-5 Dimension; HbA1c, glycated hemoglobin; LDL, lowdensity lipoprotein; PAID, Problem Areas In Diabetes scale; PAM, Patient Activation Measure; PC, primary care; SC, secondary care; SDSCA, Summary of Diabetes Self-Care Activities measure.

and the mean PAM change without a specific intervention from baseline to follow-up after 4 years was 1.4. The change ranged from 1.4 to 4.2 between different patient categories (hypertension, diabetes, asthma, heart disease and depression) and was highest in the group with the lowest baseline activation level $(+11.4)$; on the contrary, the PAM level decreased with 5.8 units in the group with the highest baseline activation level. ${ }^{7}$

Against this background, the people in our study had a low activation level with a wide range between patients. There seems room for improvement. Receiving new insights with regard to diagnosis or treatment or experiencing a new complication may decrease the level of knowledge, skills and confidence for a certain time period. Maybe the dynamic activation level changes slowly and a 1-year follow-up period is too short to result in larger changes. The observed change is less than the MCID. As Hibbard et al conclude after their 4years of follow-up study, the impact of changes in activation on outcomes, while statistically significant, appears to be limited. It may be that when activation changes, there is a time lapse between that change and when changes in outcomes can be observed. Moreover, it may be that increases in activation may have to reach a threshold before they start to meaningfully affect outcomes. An intervention specifically designed to increase and/or maintain activation might result in greater impacts. ${ }^{7}$ The implementation of our consultation model neither was specifically focused on patient activation.

Perception of diabetes changed in a positive direction, as people were significantly more conscious of the consequences of their diabetes, felt more personal control and had a more coherent understanding of their diabetes. All these perceptions were independently and positively associated with the people's activation level. ${ }^{25}$ Taken together, these findings suggest that the consultation model could enhance the person's own role in diabetes care and improve self-management possibilities. However, reported self-care activities did not change, although LDL cholesterol and BMI decreased significantly. 'More emphasis on self-management' was a specific treatment 
西

亨

हृ

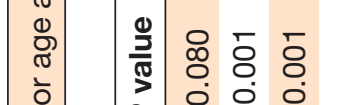

흔

ర్d

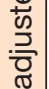

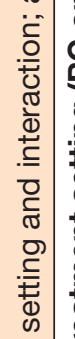

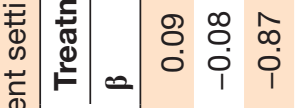

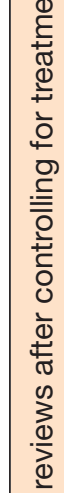

要

Nิ

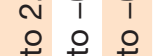

ปั

ถิ

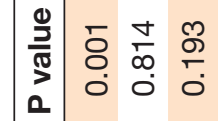

丁

में

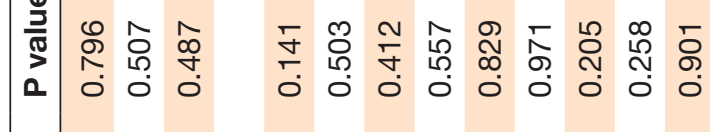

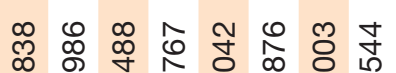

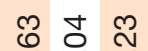

उ 웅ㅇ

드 ติ

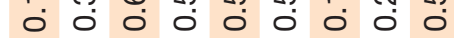

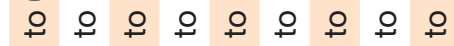

范

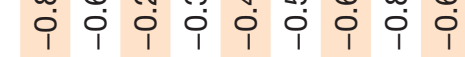

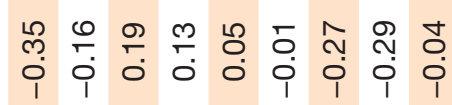

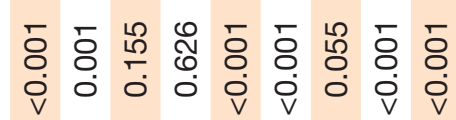

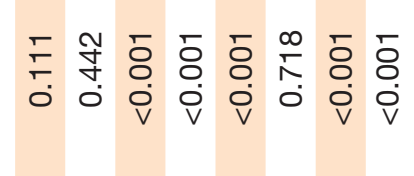

아.

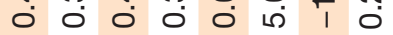

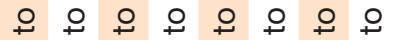

กี กิ กิ

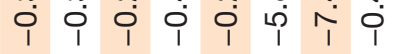

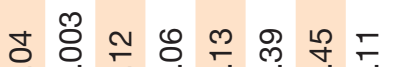

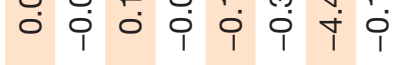

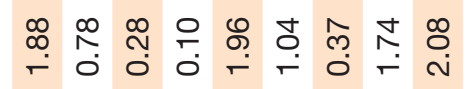

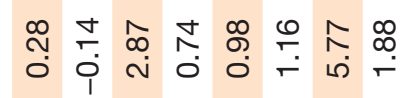

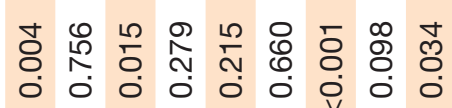

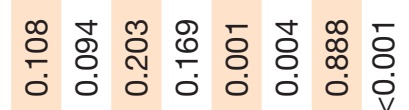

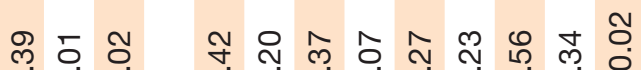

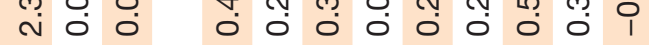

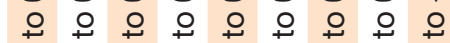

$\infty$ L

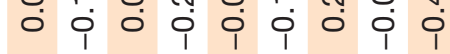

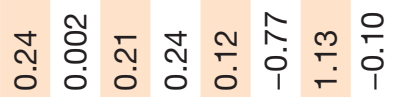

0
0

ชิ

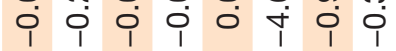

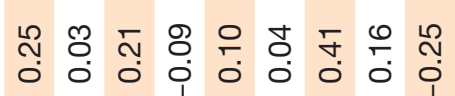

둥 둥 웅 우

के

के

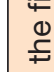

离

@

峁

$\frac{\sqrt{\frac{1}{0}}}{\frac{0}{2}}$
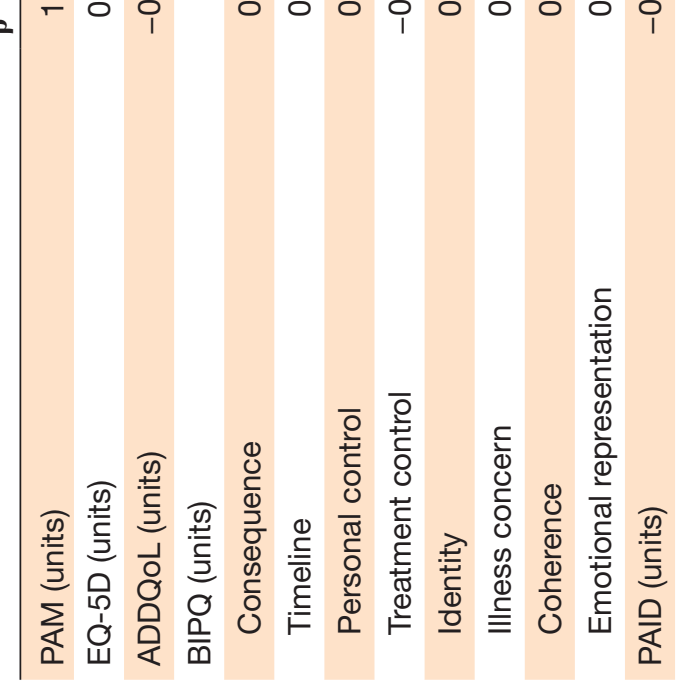

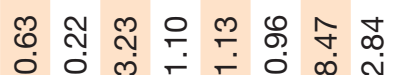

웅ㅇㅇㅇㅇㅇ

8 马े โ

i

宁。

응

엉

ฮั ত

क

츙

造高

오

을 हㅑㄹ

Ф

吕

o क

坣

ㅇำ

过 믐

爻

.0

क्ष

증 추

东 흔

बis

产

등

要这

응

든 꿀

웡

के

क व

春

ติ

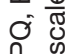

品 出

迎

용

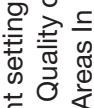


goal during the first review in only $4 \%$ of the participants. On the contrary, 1 in 6 people reported 'Loss of body weight' as a treatment goal. ${ }^{21}$ Analyzing whether these people explain the overall decrease of BMI is beyond the scope of this study, but could indicate the importance of setting treatment goals.

HbAlc increased, especially when people were treated in PC. This increase is clinically not relevant and should be assessed for each person individually. It is possible that the SDM led to more extensive discussion with the individual regarding the (dis)advantages of blood glucoselowering treatment, resulting in either no intensification or even deintensification of treatment. Overtreatment should be avoided. ${ }^{27}{ }^{28}$ Because SDM has actually been performed, ${ }^{11}$ we compared our findings with those of a systematic review of SDM in type 2 diabetes. ${ }^{29}$ The authors found a positive association between SDM and improved decision quality, person's knowledge and risk perception, but little evidence of an association between SDM and glycemic control, quality of life, medication adherence or trust in physician. In most of the studies, the intervention included the use of a decision aid. Our results are in line with these findings. In a study we performed earlier, SDM about treatment intensity and prioritization of treatment goals resulted in an HbAlc increase of $0.3 \%$ after 2 years. ${ }^{30}$ In that study, we used a so-called 'decision aid', ${ }^{31}$ considering clinical factors, the intensity of treatment and personal preferences. ${ }^{32}$ The consultation model underlying the present study did not include a decision aid, which we consider an advantage in terms of implementation, as consultations including a decision aid are likely to last longer. ${ }^{33}$

Health status and the impact of diabetes on quality of life did not change. The baseline values in the study population were good and for only $4 \%$ of the participants 'Improvement of psychological well-being' was a specified treatment goal. ${ }^{21}$

A strength of our study is its 'real life' setting. We included people in both PC and SC, with many different stages of type 2 diabetes. Although we cannot rule out selection bias and PC group practices were slightly overrepresented, the division of PC and SC patients was representative for Dutch diabetes care and the PC patients were representative for the total Dutch PC diabetes population. ${ }^{11}$ Another strength is the similarity between our consultation model and the ADA/EASD decision cycle for patient-centered glycemic management in type 2 diabetes. ${ }^{1}$

Some limitations need to be considered. First, we did not perform any formal fidelity testing of the intervention. Performing an 'implementation study', we aimed to assess what happens after a short, practical training of diabetes care providers in the concept of 'person centered care'. Most of them will develop their own approach to activate their patients. ${ }^{34}$ Whatever happened during the consultations, the vast majority of adults with type 2 diabetes stated that there was SDM about treatment goals, treatment and care. ${ }^{11}$ The follow-up period of only
1 year may have been too short to allow participants and care providers to become accustomed to their new roles in diabetes management, even though the model was implemented among receptive providers and people with type 2 diabetes. Besides, around $20 \%$ of the participants did not return to take part in the second review. While the reasons for dropout were diverse, the lack of routine regarding a person-centered annual review might have played a role.

In conclusion, a feasible diabetes review model quite similar to the ADA/EASD recommendations was associated with a slightly higher level of patient activation, improved diabetes perception and, in line with other studies, small improvements in clinical outcomes. Personcentered diabetes care may indeed enhance people's engagement in diabetes care, but it seems unrealistic to expect that the implementation of the conversation model will result in a substantial improvement in patient outcomes in the short term.

Acknowledgements The authors thank the physicians, nurses and people with type 2 diabetes who participated in this study. We also thank Paul Wester from the Julius Center, University Medical Center Utrecht, Utrecht University, for his statistical support.

Contributors All authors designed the study and interpreted the data. HVV had full access to all data of the study and takes responsibility for the integrity of the data and accuracy of the data analysis. HVV made a first draft of the manuscript. GEHMR wrote the final version.

Funding The study was financially supported by grants from the Innovation Fund of the Dutch Health Insurance Companies and from the Diabetes Fund, the Netherlands.

Competing interests None declared.

Patient consent for publication Not required.

Ethics approval Because of the character of the intervention, no ethical approval was required according to the Ethics Committee of the University Medical Center Utrecht, the Netherlands. All study procedures were in accordance with the Declaration of Helsinki. All participants provided written informed consent to use their personal data from the electronic records.

Provenance and peer review Not commissioned; externally peer reviewed.

Data availability statement Data are available from the second author upon reasonable request.

Open access This is an open access article distributed in accordance with the Creative Commons Attribution Non Commercial (CC BY-NC 4.0) license, which permits others to distribute, remix, adapt, build upon this work non-commercially, and license their derivative works on different terms, provided the original work is properly cited, appropriate credit is given, any changes made indicated, and the use is non-commercial. See: http://creativecommons.org/licenses/by-nc/4.0/.

\section{ORCID IDs}

Guy E H M Rutten http://orcid.org/0000-0001-5773-2614

Eelco de Koning http://orcid.org/0000-0002-1232-7022

\section{REFERENCES}

1 Davies MJ, D'Alessio DA, Fradkin J, et al. Management of hyperglycemia in type 2 diabetes, 2018. A consensus report by the American diabetes association (ADA) and the European association for the study of diabetes (EASD). Diabetes Care 2018;41:2669-701.

2 American Diabetes Association. 6. Glycemic Targets: Standards of Medical Care in Diabetes-2020. Diabetes Care 2020;43:S66-76.

3 Salisbury C, Man M-S, Bower P, et al. Management of multimorbidity using a patient-centred care model: a pragmatic cluster-randomised trial of the 3D approach. The Lancet 2018;392:41-50.

4 Powers MA, Bardsley J, Cypress M, et al. Diabetes self-management education and support in type 2 diabetes. A joint position statement 
of the American diabetes association, the American association of diabetes educators, and the Academy of nutrition and dietetics. Diabetes Educ 2017;43:40-53.

5 Greene J, Hibbard JH. Why does patient activation matter? an examination of the relationships between patient activation and health-related outcomes. J Gen Intern Med 2012;27:520-6.

6 Hibbard JH, Stockard J, Mahoney ER, et al. Development of the patient activation measure (PAM): Conceptualizing and measuring activation in patients and consumers. Health Serv Res 2004;39:1005-26.

7 Hibbard JH, Greene J, Shi Y, et al. Taking the long view: how well do patient activation scores predict outcomes four years later? Med Care Res Rev 2015:1-14.

8 Hibbard JH, Greene J. What the evidence shows about patient activation: better health outcomes and care experiences; fewer data on costs. Health Aff 2013;32:207-14.

9 Almutairi N, Hosseinzadeh H, Gopaldasani V. The effectiveness of patient activation intervention on type 2 diabetes mellitus glycemic control and self-management behaviors: a systematic review of RCTs. Prim Care Diabetes 2020;14:12-20.

10 Olesen K, Folmann Hempler N, Drejer S, et al. Impact of patientcentred diabetes self-management education targeting people with type 2 diabetes: an integrative review. Diabet. Med. 2020;37:909-23.

11 Rutten GEHM, van Vugt HA, de Weerdt I, et al. Implementation of a structured diabetes consultation model to facilitate a personcentered approach: results from a nationwide Dutch study. Diabetes Care 2018;41:688-95.

12 Nano J, Carinci F, Okunade O, et al. A standard set of personcentered outcomes for diabetes mellitus: results of an international and unified approach. Diabet Med 2020. [Epub ahead of print: 02 Mar 2020].

13 Hibbard JH, Mahoney ER, Stockard J, et al. Development and testing of a short form of the patient activation measure. Health Serv Res 2005:40:1918-30

14 Rademakers J, Nijman J, van der Hoek L, et al. Measuring patient activation in the Netherlands: translation and validation of the American short form patient activation measure (PAM13). BMC Public Health 2012;12:577.

15 Anderson JK, Wallace LM. Evaluation of uptake and effect on patient-reported outcomes of a clinician and patient co-led chronic musculoskeletal pain self-management programme provided by the UK National health service. Br J Pain 2018:12:104-12.

16 Rabin R, Charro Fde, de Charro F. EQ-SD: a measure of health status from the EuroQol group. Ann Med 2001;33:337-43.

17 Bradley C, Todd C, Gorton T, et al. The development of an individualized questionnaire measure of perceived impact of diabetes on quality of life: the ADDQoL. Qual Life Res 1999;8:79-91.

18 Broadbent E, Petrie KJ, Main J, et al. The brief illness perception questionnaire. J Psychosom Res 2006;60:631-7.

19 McGuire BE, Morrison TG, Hermanns N, et al. Short-form measures of diabetes-related emotional distress: the Problem Areas in Diabetes Scale (PAID)-5 and PAID-1. Diabetologia 2010;53:66-9.
20 Toobert DJ, Hampson SE, Glasgow RE. The summary of diabetes self-care activities measure: results from 7 studies and a revised scale. Diabetes Care 2000;23:943-50.

21 van Vugt HA, de Koning EJP, Rutten GEHM. Association between person and disease related factors and the planned diabetes care in people who receive person-centered type 2 diabetes care: an implementation study. PLoS One 2019;14:e0219702.

22 Hendriks M, Rademakers J. Relationships between patient activation, disease-specific knowledge and health outcomes among people with diabetes; a survey study. BMC Health Serv Res 2014;14.

23 Insignia Health. Patient activation measure (PAM) license materials. Portland: Insignia health, 2016.

24 Eikelenboom N, van Lieshout J, Jacobs A, et al. Effectiveness of personalised support for self-management in primary care: a cluster randomised controlled trial. Br J Gen Pract 2016;66:e354-61.

25 van Vugt HA, Boels AM, de Weerdt I, et al. Patient activation in individuals with type 2 diabetes mellitus: associated factors and the role of insulin. Patient Prefer Adherence 2018;13:73-81.

26 Rademakers J, Maindal HT, Steinsbekk A, et al. Patient activation in Europe: an international comparison of psychometric properties and patients' scores on the short form Patient Activation Measure (PAM13). BMC Health Serv Res 2016;16:570.

27 Lipska KJ, Ross JS, Miao Y, et al. Potential overtreatment of diabetes mellitus in older adults with tight glycemic control. JAMA Intern Med 2015;175:356-62.

28 Hart HE, Rutten GE, Bontje KN, et al. Overtreatment of older patients with type 2 diabetes mellitus in primary care. Diabetes Obes Metab 2018;20:1066-9.

29 Saheb Kashaf M, McGill ET, Berger ZD. Shared decision-making and outcomes in type 2 diabetes: a systematic review and meta-analysis. Patient Educ Couns 2017;100:2159-71.

30 Den Ouden H, Vos RC, Rutten GEHM. Effectiveness of shared goal setting and decision making to achieve treatment targets in type 2 diabetes patients: a cluster-randomized trial (Optimal). Health Expect 2017;20:1172-80.

31 Montori VM, LeBlanc A, Buchholz A, et al. Basing information on comprehensive, critically appraised, and up-to-date syntheses of the scientific evidence: a quality dimension of the International patient decision aid standards. BMC Med Inform Decis Mak 2013;13:S5.

32 den Ouden H, Vos RC, Reidsma C, et al. Shared decision making in type 2 diabetes with a support decision tool that takes into account clinical factors, the intensity of treatment and patient preferences: design of a cluster randomised (optimal) trial. BMC Fam Pract 2015;16:27.

33 Tamhane S, Rodriguez-Gutierrez R, Hargraves I, et al. Shared decision-making in diabetes care. Curr Diab Rep 2015;15:112.

34 Greene J, Hibbard JH, Alvarez C, et al. Supporting patient behavior change: approaches used by primary care clinicians whose patients have an increase in activation levels. The Annals of Family Medicine 2016;14:148-54. 